\title{
Quantitative Measurement Method of Contact Stiffness of the Joint with Different Material Combination*
}

\author{
Shinji SHIMIZU**, Kyoko NAKAMURA ${ }^{* * *}$ and Haruhisa SAKAMOTO** \\ **Department of Engineering and Applied Sciences, Sophia University, \\ 7-1 Kioi-cho, Chiyoda-ku, Tokyo 102-8554, Japan \\ E-mail: s_shimizu@sophia.ac.jp \\ ${ }^{* * *}$ Department of Graduate School of Science and Technology, Sophia University, \\ 7-1 Kioi-cho, Chiyoda-ku, Tokyo 102-8554, Japan
}

\begin{abstract}
The joints in machine tools influence greatly the static, dynamic and thermal characteristics of the machines. Then the many researches on them have been carried out. Under these conditions, the authors have established the quantitative measurement method of contact stiffness of the joint with same material combination considering the real contact area, since the real contact area is far smaller than the nominal contact area. In this research, we propose the new measurement method of contact stiffness of the joint with different material combination expanding the former method we developed and its validity is considered. In consequence, the following results are obtained. 1) The measurement method applicable to the joint with various material combinations is established using inserted specimens. 2) The real contact area of the joint with different material combination can be accurately measured considering the reflected level of ultrasonic wave at the real contact area of the joint. 3) The contact stiffness of the joint with different material combination can be treated as the series coupling of the each contact stiffness constructing the joint. 4) The contact stiffness of the joint and each contact stiffness of the contact springs constructing the joint can be measured by the proposed method.
\end{abstract}

Key words: Machine Tool, Contact Stiffness, Joint, Real Contact Area, Different Materials Combination, Ultra-sonic Wave

\section{Introduction}

It is known that joints in machine tools influence greatly the static, dynamic and thermal characteristics of the machines. Then the many researches on them have been carried out. Ito ${ }^{(1)}$ has written an academic book from the standpoint of machine tool design in which these research results were introduced with his research results. Since the static characteristic influences the other characteristics, many researches have been done on the formulation for the contact stiffness of the joint and the others. For example, Buc ${ }^{(2)}$ and Johnson ${ }^{(3)}$ have made a model of the joint surface considering its roughness and profile and they have examined the relationship between force and contact ratio of the joint interface. In addition to this, Ostrovskii ${ }^{(4)}$ and Levina ${ }^{(5)}$ have considered the contact stiffness of the joint and revealed that the relationship between approaching distance $\delta$ and mean contact pressure $P$ can be shown as follow.

Received 17 Feb., 2010 (№. 10-0091) [DOI: 10.1299/jamdsm.4.1044]

Copyright () 2010 by JSME 


$$
\delta=C P^{m}
$$

where $C$ and $m$ are constants which depend on material property, roughness and machining method of the joint surface. The value of $C$ and $m$ are examined by Back $^{(6)}$ based on experimental data.

These researches are carried out based on the nominal contact area. However, it has revealed that the real contact area is far smaller than the nominal contact area ${ }^{(7)}$, since the joint surfaces have not always ideal flatness. Then, we ${ }^{(8)}$ have proposed the quantitative measurement method of the contact stiffness of the joint with same material combination considering the real contact area.

In the mean time, various materials such as concrete and ceramics became to be used for the structural materials for recent machine tools in addition to cast iron and steel. Then the joints with different material combination are also increasing.

Therefore, in this study, we consider the quantitative measurement method of the contact stiffness of the joint with different material combination. To measure quantitatively the contact stiffness of the joint, the approaching distance of the joint interface and the real contact area under the loading are necessary to be measured accurately. However, the measurement method for the joint with same material combination cannot be applied to the joint with different material combination. Then in this paper, we propose a new quantitative measurement method of the contact stiffness of the joint with different material combination.

\section{Principle of identification of joint contact stiffness}

Figure 1 shows the relationship between the joint force $F$ and the approaching distance of the joint interface $\delta . K$ is the overall contact stiffness in a small range of the joint force and it is not constant to the force. However, authors have shown that the $k$ obtained by dividing $K$ with the real contact area $A_{r}$ at the force applied is constant for every force range $^{(9)}$.

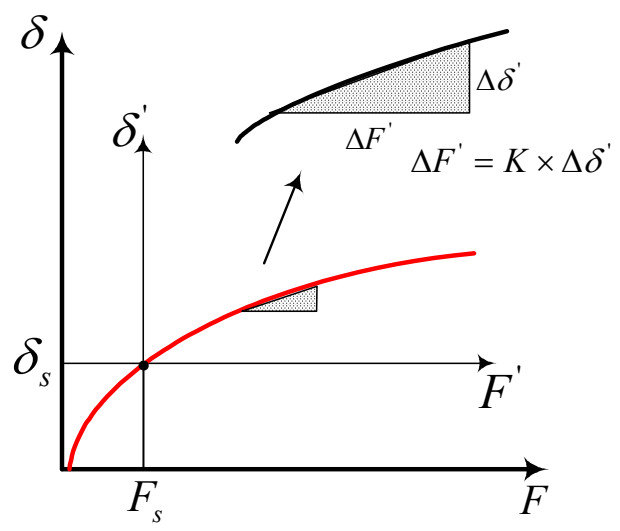

Fig. 1 Relationship between the joint force and the approaching distance of the joint interface

Furthermore, we have also revealed that the relationship between the force $F$ and the distance $\delta$ is given by the following equation with the increase rate $t$ of the real contact area and this validity has been shown ${ }^{(9)}$.

$$
\delta=\delta^{\prime}+\delta_{s}=\frac{1}{k \times t} \ln \left(\frac{F_{s}+F^{\prime}}{F_{s}}\right)+\delta_{s}
$$


where $\delta^{\prime}$ and $\delta_{s}$ are the approaching distance at the load of $F^{\prime}$ and $F_{s}$ respectively. The contact stiffness of the joint $k$ can be identified from this Eq. (2) and the experimental data.

\section{Measurement device and method}

\subsection{Measurement device and experimental condition}

Figure 2 shows the outline of the measurement device for this research. Basically, the approaching distance and real contact area can be measured by constructing the joint interface with the upper and lower specimens. Load on the joint interface is applied by a bolt and detected by a piezo electric transducer. Furthermore, the approaching distance of the joint interface is measured by eddy current sensors and the real contact area is measured by a ultrasonic flaw detector. Upper and lower specimens are made of medium carbon steel $\mathrm{S} 45 \mathrm{C}$, and the diameter, roughness and flatness of the both joint surfaces are $\phi 32, \mathrm{Ra}$ $0.01 \mu \mathrm{m}$ and Wa $0.02 \mu \mathrm{m}$ respectively.

In addition, we adopt a way inserting the specimen with different material into the joint interface to measure the contact stiffness of the joint with different material combination. Figure 3 shows the experimental model for this research. Figure (a) shows the model with inserted specimen and Fig. (b) shows solid model to compensate the elastic deformation excepting for the joint interface. Moreover, Table 1 shows the condition of specimens for this research. A7075 is high-strength aluminum alloy, $\mathrm{Cu}$ is pure copper and FC is grey cast iron FC200. All inserted specimens are ground and their roughness is Ra $0.13 \mu \mathrm{m} \sim 0.25 \mu \mathrm{m}$ and their waviness is Wa $0.08 \mu \mathrm{m} \sim 0.16 \mu \mathrm{m}$. $R$ in the table is coefficient of reflection described below of the ultrasonic wave at the joint interface with different material combination $^{(10)}$.

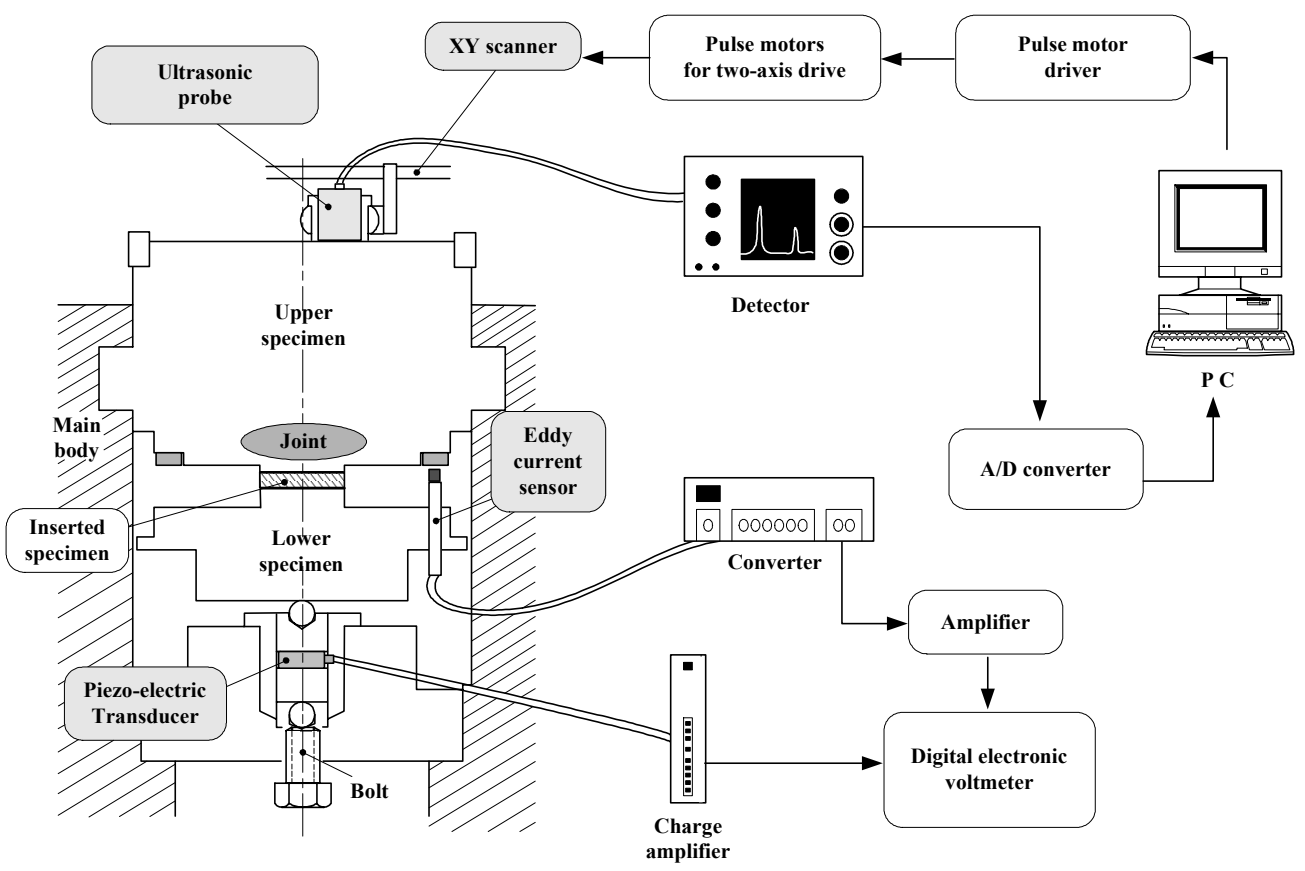

Fig. 2 Outline of the measurement device for the research 


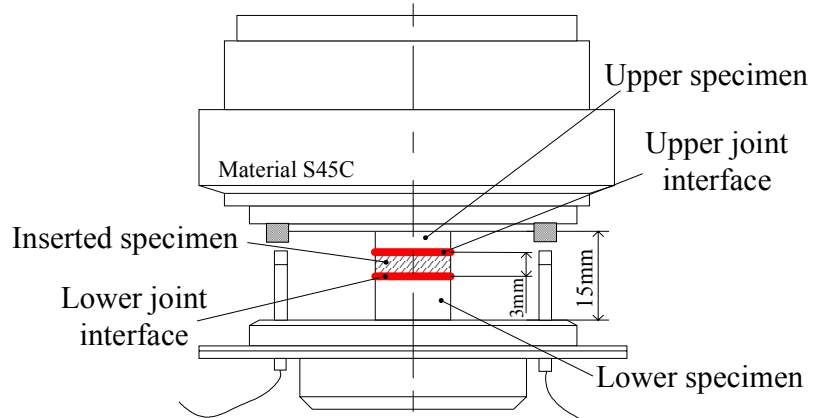

(a) Model with double joint interface

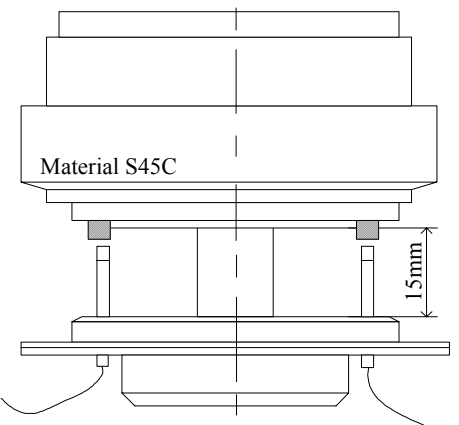

(b) Solid model

Fig. 3 Experimental model for the measurement

Table.1 Condition of specimens

\begin{tabular}{|c|c|c|}
\hline \multicolumn{3}{|c|}{ Joint material combination : $\mathrm{S} 45 \mathrm{C}-\mathrm{S} 45 \mathrm{C}$} \\
\hline \multirow{2}{*}{\multicolumn{2}{|c|}{$\begin{array}{c}\text { Longitudinal elastic modulus E of S45C } \\
\text { Coefficient of reflection } \mathrm{R}\end{array}$}} & $205 \mathrm{GPa}$ \\
\hline & & 0 \\
\hline \multirow{2}{*}{ Roughness } & upper\&lower & Ra0.01 \\
\hline & inserted & Ra0.08, 0.17 \\
\hline \multirow{2}{*}{ Flatness } & upper\&lower & $\mathrm{Wa} 0.02$ \\
\hline & inserted & $\mathrm{Wa} 0.08$ \\
\hline \multicolumn{3}{|c|}{ Joint material combination : S45C-A7075 } \\
\hline \multicolumn{2}{|c|}{ Longitudinal elastic modulus E of A7075 } & 72GPa \\
\hline \multicolumn{2}{|c|}{ Coefficient of reflection $\mathrm{R}$} & 0.457 \\
\hline \multirow{2}{*}{ Roughness } & upper\&lower & Ra0.01 \\
\hline & inserted & $\operatorname{Ra} 0.25$ \\
\hline \multirow{2}{*}{ Flatness } & upper\&lower & $\mathrm{Wa} 0.02$ \\
\hline & inserted & $\mathrm{Wa} 0.17$ \\
\hline
\end{tabular}

\begin{tabular}{|c|c|c|}
\hline \multicolumn{3}{|c|}{ Joint material combination : $\mathrm{S} 45 \mathrm{C}-\mathrm{Cu}$} \\
\hline \multicolumn{2}{|c|}{ Longitudinal elastic modulus $\mathrm{E}$ of $\mathrm{Cu}$} & $117 \mathrm{GPa}$ \\
\hline \multicolumn{2}{|c|}{ Coefficient of reflection $\mathrm{R}$} & 0.020 \\
\hline \multirow{2}{*}{ Roughness } & upper\&lower & $\overline{\mathrm{Ra} 0.01}$ \\
\hline & inserted & $\mathrm{Ra} 0.13$ \\
\hline \multirow{2}{*}{ Flatness } & upper\&lower & $\mathrm{Wa} 0.02$ \\
\hline & inserted & Wa0.12 \\
\hline \multicolumn{3}{|c|}{ Joint material combination : $\mathrm{S} 45 \mathrm{C}-\mathrm{FC}$} \\
\hline \multicolumn{2}{|c|}{ Longitudinal elastic modulus E of FC } & $152 \mathrm{GPa}$ \\
\hline \multicolumn{2}{|c|}{ Coefficient of reflection $\mathrm{R}$} & 0.053 \\
\hline \multirow{2}{*}{ Roughness } & upper\&lower & $\mathrm{Ra} 0.01$ \\
\hline & inserted & $\mathrm{Ra} 0.19$ \\
\hline \multirow{2}{*}{ Flatness } & upper\&lower & $\mathrm{Wa0} 02$ \\
\hline & inserted & Wa0.16 \\
\hline
\end{tabular}

3.2 Measurement method of real contact area of the joint with different material combination

Figure 4 shows the models for the condition of ultrasonic wave at the joint interface. Figure (a) shows the case of same material combination and (b) shows the case of different material combination.

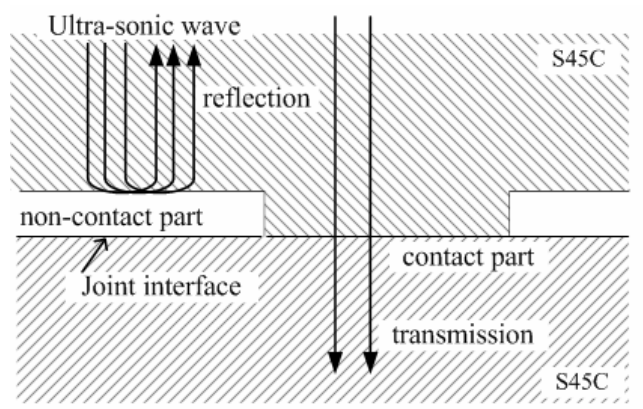

(a) Joint with same material combination

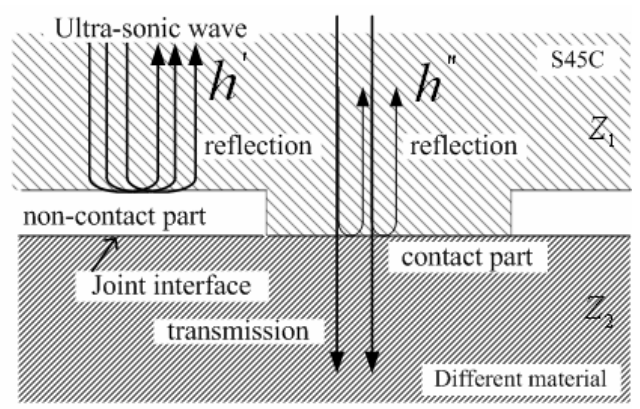

(b) Joint with different material combination

Fig. 4 Condition of ultrasonic reflection at the joint interface.

Ultrasonic wave is transmitted all at the contact area of the joint with same material combination. However, in the case of the joint with different material combination, it is known that the ultrasonic wave is reflected also at the contact area, and this characteristic of reflection is given by the coefficient of reflection $R$ as follow ${ }^{(11)}$. 


$$
R=\frac{Z_{2}-Z_{1}}{Z_{1}+Z_{2}}
$$

where $Z_{i}\left[N \cdot s / m^{3}\right]$ is acoustic impedance of each materials of jointed specimens. Reflected level $h$ of the ultrasonic wave at the interface of the joint with different material combination is given by

$$
h=h^{\prime}+h^{\prime \prime}=\left(1-E r^{*}\right) \cdot h_{0}+R \cdot E r^{*} \cdot h_{0}
$$

where, $h^{\prime}$ is reflected level at the non-contact area, $h^{\prime \prime}$ is that of the contact area and $E r^{*}$ is contact ratio of joint interface. Therefore, $E r^{*}$ at joint interface with different material combination is given by

$$
E r^{*}=\frac{1}{1-R}\left(1-\frac{h}{h_{0}}\right)
$$

Hence, the real contact area $A_{r}$ is given by as follow with the nominal contact area $A$.

$$
A_{r}=A \times E r^{*}
$$

\subsection{Estimation method of contact stiffness of the joint with single interface}

The measurement device in this study can measure the real contact area of only upper joint interface. However, for the approaching distance of the joint, the both of approaching distance for the upper and lower joint interface cannot avoid to being included in measured value. Therefore, it is necessary to consider this condition when estimating the contact stiffness.

Figure 5 shows the experimental models to consider this condition. Figure (a) shows a double-joint interface model with the inserted specimen. Figure (b) shows a single-joint interface model which integrates the inserted specimen with the lower specimen. By using these models, we consider the estimation method of contact stiffness of only single joint interface from the double-joint interface model. The material of two models is S45C.

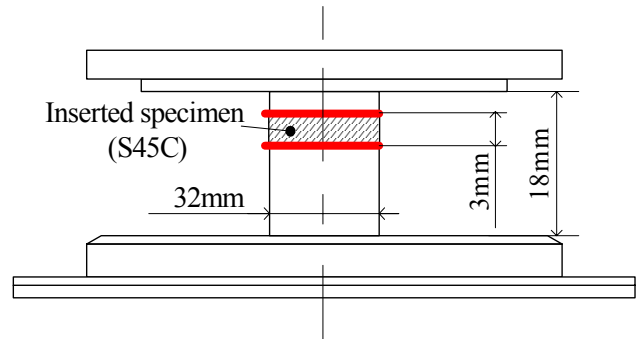

(a) Double-joint interface model

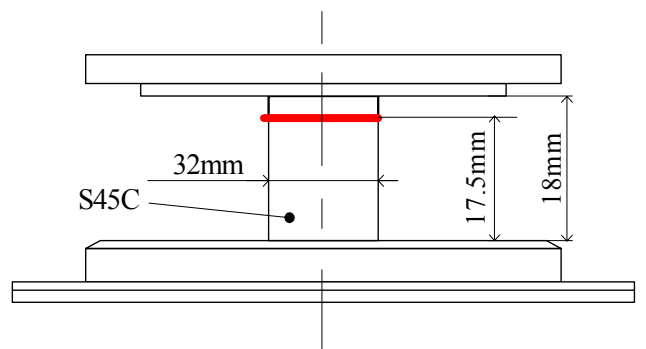

(b) Single-joint interface model

Fig.5 Experimental model for estimation of the stiffness of single joint interface

Figure 6 shows the relationship between the force and the real contact area of these joints in two models. Since (a) in Fig. 5 has two joint interfaces, initially we measured the interface which contacts with the upper specimen and then turn this specimen upside down and measure the interface which contacts with the lower specimen. The value of the double-joint interface model in Fig. 6 is average of this two measured value. 


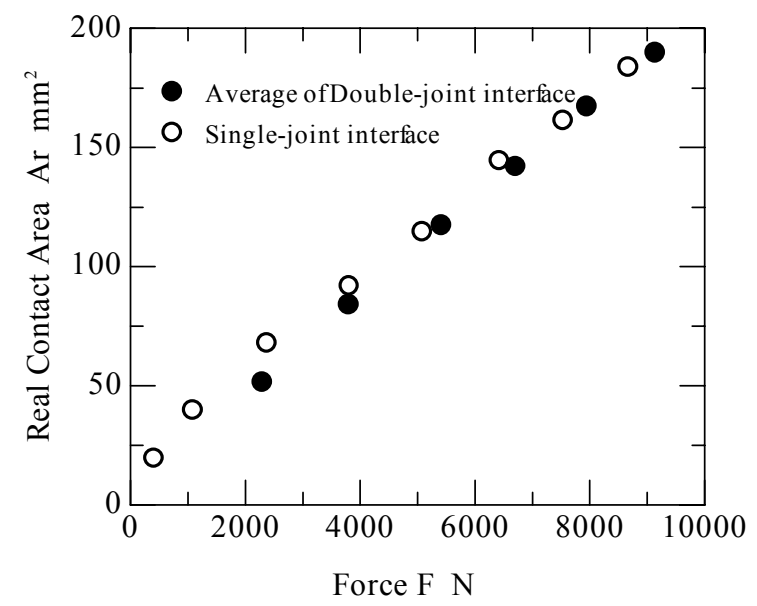

Fig.6. Real contact area of single and double joint interface models

As shown in this figure, the real contact area of both joint models under the same load is nearly equal and then we can say that the condition of the joint in these models is nearly same.

Table 2 shows measurement result of the contact stiffness using these models under the condition above. The contact stiffness of the single-joint interface model is almost twice of the stiffness of the double joint interface model. This indicates that upper and lower contact stiffness can be treated as series coupling of contact springs. Therefore, the contact stiffness of the single joint interface can be obtained by multiplying the contact stiffness of the double-joint interface model by 2 .

Table2. Contact stiffness of single and double joint interface models

\begin{tabular}{c|c}
\hline model & $\mathrm{k}$ (average) $\left[\mathrm{N} / \mathrm{mm} / \mathrm{mm}^{2}\right]$ \\
\hline \hline Double-joint interface mode & $2.87 \mathrm{E}+05$ \\
\hline Single-joint interface model & $5.72 \mathrm{E}+05$ \\
\hline
\end{tabular}

\section{Result and consideration}

\subsection{Contact stiffness of the joint with different material combination}

Figure 7 shows the approaching distance of the joint interface under loading in the case of the joint with material combination of S45C and A7075. The solid line in this figure is obtained by fitting those data to Eq. (2). This line corresponds well with experimental value and then it can be said that the Eq. (2) can apply also to the joint with different material combination.

Figure 8 shows the relationship between the force and the real contact area of the joint with material combination of S45C and A7075. The plots of solid circle show the real contact area considering the coefficient of reflection $R$ with Eq. (5). In addition, the plot of open circle shows the real contact area without consideration of $R$. Since the probe measures the ultra-sonic wave reflected from the contact area, the value without consideration of $R$ is much lower than that with consideration of $R$. Therefore, it becomes clear that the consideration of $R$ influences greatly on the measurement result of the real contact area of the joint with different material combination. 


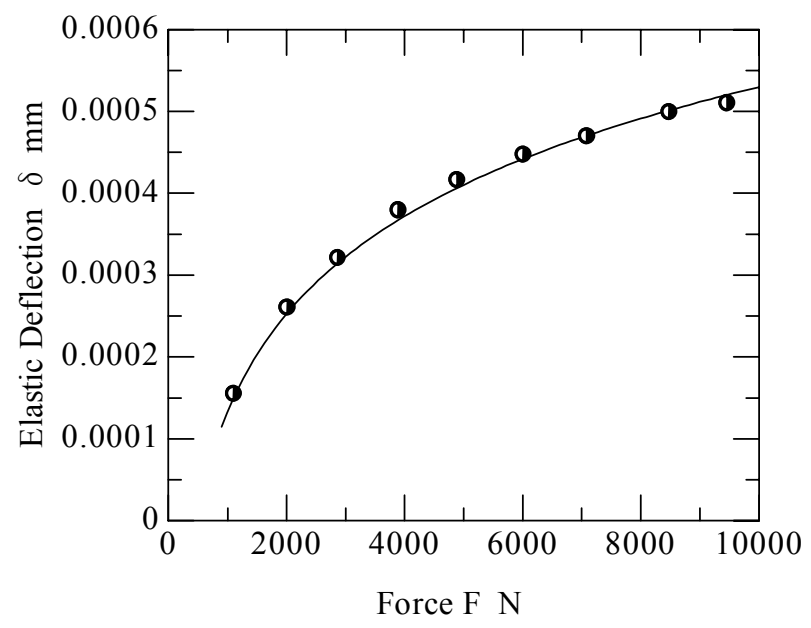

Fig.7 Approaching distance of the joint interface under the load Material combination : S45C-A7075

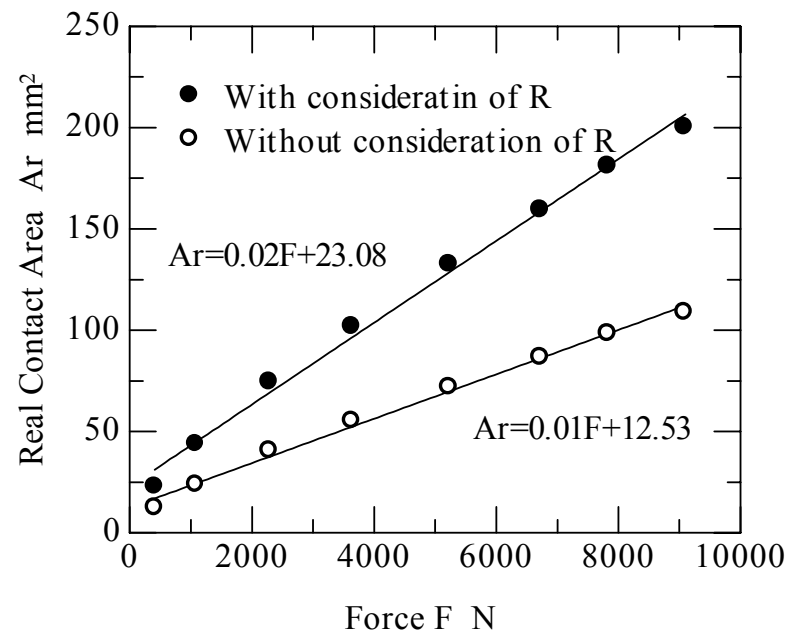

Fig. 8 Relationship between the force and the real contact area Material combination: S45C and A7075

Figure 9 is the measurement result of $k$ for the joint with material combination of S45C and A7075. The values of $k$ show good repeatability for 4 measurements.

Figure 10 shows the relationship between the contact stiffness per real contact area $k$ for the joint with various material combinations shown in Table 1 and the modulus of longitudinal elasticity of each material. This figure shows that the more the longitudinal elastic modulus is large, the more stiffness $k$ becomes large.

From these results, it can be said that we can estimate stably the contact stiffness of the joint with the different material combination with the proposed measurement method. 


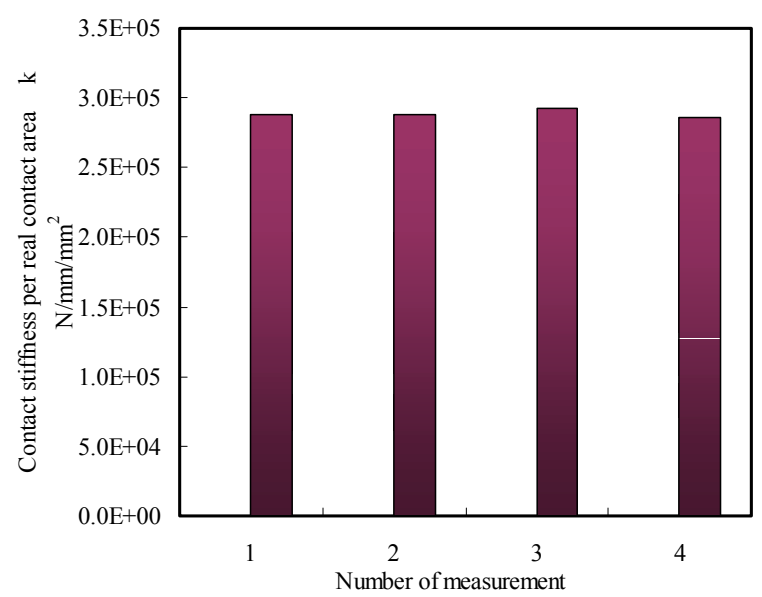

Fig.9 Contact stiffness per unit real contact area

Material combination:S45C-A7075

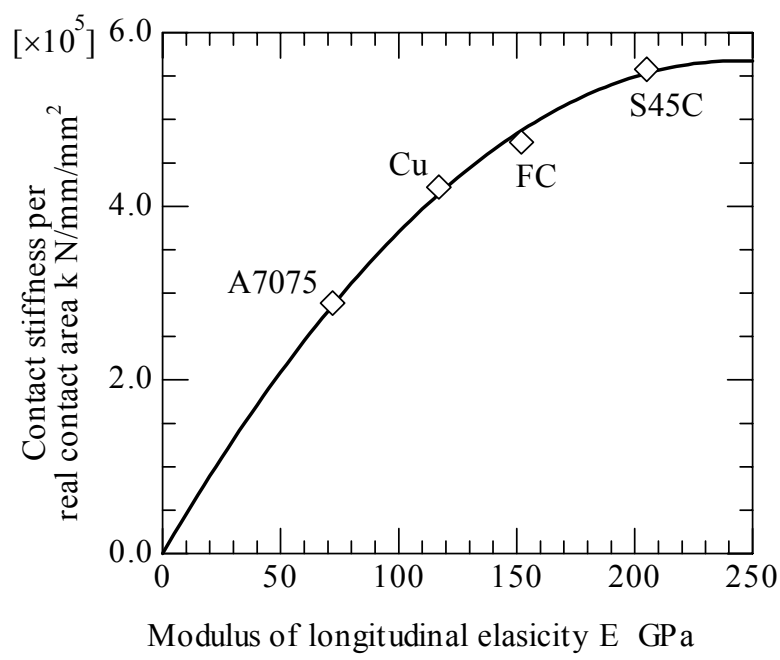

Fig.10 Relationship between the contact stiffness of the joint with different material combination $\mathrm{k}$ and their modulus of longitutinal elasticity $E$

\subsection{Consideration of validity of the proposed method}

As made clear in $\S 3.2$, it can be said that the contact stiffness per real contact area seems to be composed of series coupling of contact springs of each jointed material. Figure 11 shows models for this condition. Figure (a) shows the joint with same material combination and (b) shows the joint with different material combination. We will consider the validity of the method proposed above by obtaining $k_{2}$ of each material and examining the relationship with longitudinal elastic modulus $E$ in the next place.

As describe above, since the contact stiffness per real contact area $k$ seems to be composed of series coupling of the contact springs of each jointed material, it is given by the following equation for the joint with different material combination.

$$
\frac{1}{k}=\frac{1}{k_{1}}+\frac{1}{k_{2}}
$$




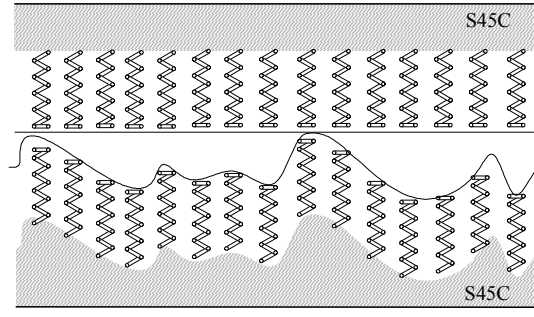

(a) Joint with same material combination

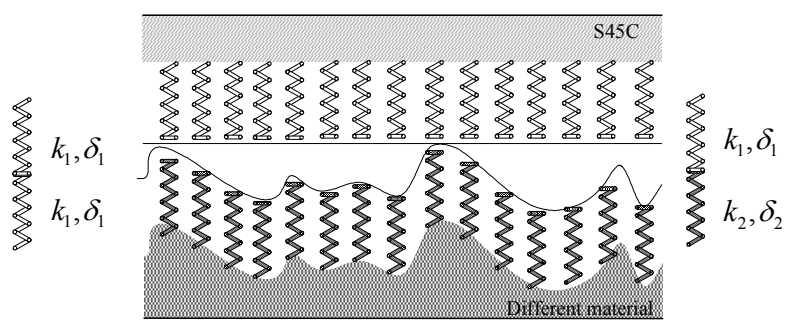

(b) Joint with different material combination

Fig.11 Spring model of the contact stiffness of the joint interface

where $k_{1}$ is contact stiffness per real contact area of upper specimen and $k_{2}$ is the contact stiffness of the inserted specimen with various materials. In this research, $k_{l}$ can be obtained from the contact stiffness $k$ with material combination of S45C-S45C. Hence, the contact stiffness $k_{2}$ required to obtain is given by

$$
k_{2}=\frac{k k_{1}}{k_{1}-k}
$$

Figure 12 shows the relationship between the stiffness $k_{2}$ calculated by Eq. (8) and longitudinal elastic modulus $E$ of the inserted specimen. As shown in this figure, it is revealed that $k_{2}$ is proportional to longitudinal elastic modulus $E$. This result corresponds with the theoretical result that the contact stiffness between a flat surface and a projection of a surface roughness is proportional to the longitudinal elastic modulus $E$ of the material ${ }^{(12)}$. Therefore, this seems to show the validity of the method proposed in this research. In addition, since the contact stiffness of each material can be obtained as described above, the contact stiffness of the joint interface with different material combination seems to be able to estimate by using Eq. (7) in addition to combination S45C-various materials.

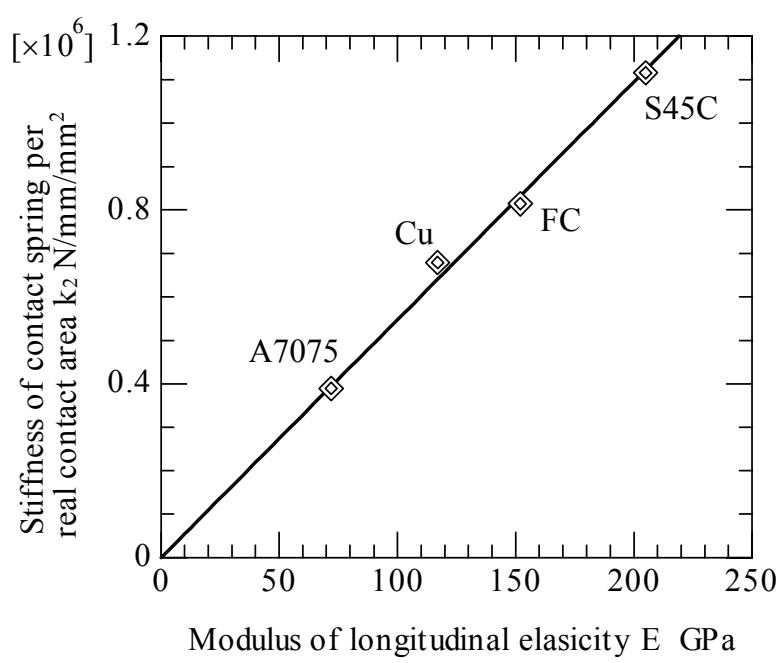

Fig.12 Relationship between the stiffness of contact spring and the modulus of longitudinal elasticity 


\section{Conclusion}

In consequence of considering the quantitative measurement method of contact stiffness of the joint with different material combination, following results are obtained.

(1) The real contact area of the joint with different material combination can be accurately measured considering the reflected level of ultrasonic wave at the real contact area of the joint.

(2) The contact stiffness of the joint with single interface can be obtained by multiplying the contact stiffness of the joint with double interface by 2 .

(3) The contact stiffness of the joint with different material combination can be treated as the series coupling of the each contact stiffness constructing the joint.

(4) The contact stiffness of a joint surface constructing the joint with different material combination can be obtained by using the proposed method.

(5) Based on these result, the contact stiffness per real contact area with different material combination can be obtained quantitatively.

\section{References}

(1) Yoshimi Ito, Modular design for machine tools, The McGraw-Hill Companies Inc, (2008), pp175-279

(2) J.Buc and B.Nowicki:The measurement of the real area of contact between two metal surface, Proc. of the 8th Int.MTDR Conf., Part2, (1967) pp.213-414

(3) K.L.Johnson, Contact mechanics, Cambridge Univ.Press, Cambridge, (1985) pp.397-423

(4) V.I.Ostrovskii, The influence of machining methods on slideway contact stiffness, Machines and Tooling, (1965), pp.17-19

(5) Z.M.Levina, Research on the static stiffness of joint in machine tools, Proc. of the 8th Int.MTDR Conf., Part2, (1967), pp.737-758

(6) Back. N, M.Burdekin and A.Cowley, Review of the research on fixed and sliding joints, Proc. 13th Inter MTDR Conf, (1972), pp.87-97

(7) S. Shimizu, K.Kikumori, H.Sakamoto and K.Tamaoki, Quantitative measuring method of thermal contact resistance considering real contact area, Journal of JSPE, Vol71, No8, (2005), pp.1026-1030, (in Japanese).

(8) Shinji Shimizu, Shinji Hirakata and Haruhisa Sakamoto, Identification method of contact stiffness of joint, Proceedings of annual spring meeting of JSPE in 2003, (2003), p.195 (in Japanese).

(9) S.Shimizu, S.Honda, H.Sakamoto and S.Yagyu, Method of Finite Element Analysis for the Behavior of Bending Deformation of Structure with a Joint -Precise identification method of joint contact stiffness-, Proceeding of annual autumn meeting in 2007 of JSPE, (2007), pp.5-6 (in Japanese).

(10) National Astronomical Observatory, Chronological Scientific Tables 2000, Maruzen, (2000), pp.453-457 (in Japanese)

(11) N.Suzuki, Hand book of ultra-sonic wave, Editorial Committee for the hand book of ultra-sonic wave, Maruzen, (1999), pp.21-24 (in Japanese).

(12) G.M.Pharr, W.C.Oliver and F.R.Brtzen, On the generality of the relationship among contact stiffness, contact area, and elastic modulus during indentation, Journal of Materials Research, Vol.7, No.3, (1992), pp.613-617 